\title{
ПУБЛИКАЦИИ
}

DOI: https://doi.org/10.15688/nav.jvolsu.2019.1.13

UDC 902.21

Submitted: 15.01.2019

LBC 63.443.2

Accepted: 02.03.2019

\section{THE MATERIALS TO THE PORTHMION CHRONOLOGY}

\author{
Roman V. Stoyanov \\ Institute for the History of Material Culture, RAS, \\ Saint-Petersburg, Russian Federation
}

\begin{abstract}
The Bosporus expedition of the Institute for the History of Material Culture of the Russian Academy of Sciences conducted a small archaeological research in the northwestern sector of Porthmion in 2002-2003. Two exploration trenches were laid on the excavation area. Archaeological assemblages of the trenches contain information on historical chronology of the settlement.

The fire-destruction layer recorded in trench 1 marks the period of destabilization of Greek-barbarian relations in the region, probably connected with the activity of nomadic tribes during the early $5^{\text {th }} \mathrm{c}$. BC. The foundations of the residential building identified in trench 2 refer to the $4^{\text {th }} \mathrm{c}$. BC. This period was associated with the relatively calm reign of the Spartokids dynasty in the Bosporus. Traces of active building dating back to the early $2^{\text {nd }} \mathrm{c}$. $\mathrm{BC}$ are associated with the period of the so-called Bosporus "cultural revival", which took place against a background of stabilization in the region after the Sarmatian invasion.

Key words: the Northern Black Sea region, the Bosporus, Porthmion, archaeological assemblage, trench, trade amphorae, pottery, chronological period.

Citation. Stoyanov R.V., 2019. The Materials to the Porthmion Chronology. The Lower Volga Archaeological Bulletin, vol. 18, no. 1, pp. 165-177. (in Russian). DOI: https://doi.org/10.15688/nav.jvolsu.2019.1.13

УДК 902.21

Дата поступления статьи: 15.01.2019

ББК 63.443 .2

Дата принятия статьи: 02.03.2019
\end{abstract}

\section{МАТЕРИАЛЫ К ХРОНОЛОГИИ ПОРФМИЯ}

\section{Роман Владимирович Стоянов}

Институт истории материальной культуры РАН, г. Санкт-Петербург, Российская Федерация

\footnotetext{
Аннотация. В 2002-2003 гг. Боспорской экспедицией ИИМК РАН проводились небольшие исследования в северо-западном районе Порфмия. На исследуемой площади были заложены два разведочных шурфа. Стратиграфия последних и найденные в них материалы содержат сведения об исторической хронологии городища. Слой пожара, зафиксированный в шурфе 1, маркирует период дестабилизации греко-вар亏े варских взаимоотношений в регионе, вероятно, связанной с активизацией кочевых племен в первой половине V в. до н.э. Фундаменты жилой постройки, выявленные в шурфе 2, относятся к IV в. до н.э. На Боспоре этот период был связан со сравнительно спокойным правлением династии Спартокидов. Следы активного строительства относятся к первой половине II в., связаны с периодом так называемого «культурного возрождения» Боспора, происходившего на фоне относительной стабилизации взаимоотношений в регионе после сарматского нашествия.
} 
Ключевые слова: Северное Причерноморье, Боспор, Порфмий, археологический комплекс, шурф, тарные амфоры, керамика, хронологический период.

Цитирование. Стоянов Р. В., 2019. Материалы к хронологии Порфмия // Нижневолжский археологический вестник. Т. 18, № 1. С. 165-177. DOI: https://doi.org/10.15688/nav.jvolsu.2019.1.13

Археологические исследования городища, расположенного в Восточном Крыму и отождествляемого с древним Порфмием, были начаты в 1953 г. экспедицией ЛОИА АН СССР под руководством В.Ф. Гайдукевича и впоследствии продолжены в 1968 и 19711982 гг. под руководством Е.Г. Кастанаян. В результате проведенных раскопок были получены данные о пространственной организации и исторической хронологии этого памятника. Время существования городища датировано второй половиной VI - началом I в. до н.э. В конце III - первой половине II в. до н.э. Порфмий был существенно перестроен после разрушений, связанных с агрессией со стороны варварских племен, обусловленной изменением геополитической ситуации в степной зоне Северного Причерноморья в конце IV - первой половине III в. до н.э. [Кастанаян, 1958, с. $207 ; 1971$, c. $188,190-191 ; 1972$, с. $81-82$; 1975 , c. $103 ; 1987$, p. 166-168].

В 1986-1990 гг. и с 2002 г. до настоящего времени исследования Порфмия проводятся отрядом Боспорской экспедиции ИИМК $\mathrm{PAH}^{1}$. За это время были получены принципиально новые материалы: открыты строительные комплексы позднеархаического периода, начаты систематические исследования городского некрополя. Полученные данные не только расширили круг источников по истории городища, но позволили дополнить и уточнить сделанные ранее выводы ${ }^{2}$.

В 2002-2003 гг. сотрудниками экспедиции были проведены небольшие исследования в северо-западном районе Порфмия. Причиной указанных работ стали разрушения, которым подверглась эта часть памятника. В 2002 г. здесь были зафиксированы многочисленные грабительские ямы размерами от $0,3 \times 0,2$ до $1,5 \times 2$ м (рис. 1). После фиксации крупные ямы были засыпаны, а обнаруженный в них материал - разобран, учтен и удален с территории памятника. Глубокие ямы, нарушившие культурный слой в западной части городища, в непосредственной близости от северной эллинистической оборонительной стены, были расчищены, их стенки выровнены, а стратиграфия изучена до уровня, на который углубились грабители. Условно эти небольшие участки раскопок были названы шурфами 1 и 2 (рис. 1,1-3). Целью работ было получение информации о разрушенных объектах и уточнение уже имеющихся данных о свите культурных напластований и хронологии северо-западной части городища. Описания и характеристика открытых площадей, а также историческая и хронологическая интерпретация полученных материалов представлены ниже.

На исследуемой площади были заложены два разведочных шурфа (рис. 1-3). Шурф 1 размером $3 \times 4$ м был разбит над грабительскими ямами, находившимися на расстоянии 0,2 м от северной оборонительной стены городища и 20 м от северо-западной угловой башни. Первая яма, вероятно, более ранняя, имела размер около $1,3 \times 1,4$ м. Вторая яма размером около $2 \times 1,7$ м частично перекрывала первую. Ямы перерезали и частично разрушили постройки, располагавшиеся в этой части квартала. На поверхности были беспорядочно разбросаны разноразмерные известняковые блоки подпрямоугольной формы со следами обработки, некоторые из них (длиной до 0,8 м), вероятно, принадлежали кладке оборонительной стены (рис. 1,2).

У фундамента оборонительной стены был зафиксирован слой подсыпки под основанием нижнего ряда кладки. Эта же подсыпка, состоящая из мелких необработанных кусков известняковой крошки и глины толщиной около 0,4 м, была выявлена вдоль западного и восточного бортов шурфов 1-2 (рис. 2,2). Описываемый слой, по всей видимости, маркирует уровень нивелировки поверхности, относившейся ко времени застройки городища в первой половине II в. до н.э. Наиболее полно слой строительной нивелировки сохранился в западной части шурфа, где он был прослежен на площади 3,8 × 1 м. При разборке этого слоя были найдены немногочисленные фрагменты стенок тарных амфор и столовой керамики. Кроме того, в слое были найдены две бронзо- 
вые пантикапейские монеты, относящиеся к первой половине II в. до н.э. (см. таблицу и рис. 4).

Ниже строительной нивелировки на всех непотревоженных участках был выявлен золистый слой толщиной около 0,3-0,6 м, содержавший куски обгорелой древесины и штукатурки (рис. 2). Этот слой мог образоваться только в результате разрушений и пожара. Среди находок из золистого слоя следует отметить трехлопастный втульчатый наконечник стрелы и часть дна чернолакового скифоса с граффито «А» на внешней стороне (рис. 5). Фрагмент, по всей видимости, принадлежал сосуду первых десятилетий V в. до н.э. [Sparkes, Tallkot, 1970, nrs. 339-342].

Шурф 2 размерами 3,2 × 2,5 м был заложен на расстоянии около 15 м к востоку от северо-западной угловой башни Порфмия и 0,2 м - от внутреннего фаса кладки оборонительной стены (рис. 1,3; 6). В выбросе из грабительской ямы были найдены обломки венцов мендейских амфор пифоидного типа, датируемых в пределах первой половины - третьей четверти V в. до н.э. ${ }^{3}$, и часть ножки лесбосской амфоры архаического типа, вероятно, относящейся к первой половине V в. до н.э. [Монахов, 2003, с. 48, 49, 89, 90]. Здесь же были найдены обломки коричневоглиняной кастрюли, нижняя часть красноглиняной миски и обломок каменной крышки пифоса (рис. 7,1-3).

Верхний слой, выявленный по всей площади шурфа на глубине от 0,15 до 0,9 м, представлял собой рыхлый суглинок темно-коричневого цвета, практически не содержавший находок. По всей видимости, этот слой принадлежал засыпке, относившейся ко времени раскопок городища под руководством Е.Г. Кастанаян (см. выше). Под ним в юго-западной части шурфа на площади $1 \times 1,5$ м была, как и в шурфе 1, выявлена строительная подсыпка первой половины II в. до н.э. (рис. 2).

В северной части шурфа 2 были открыты внутренние фасы стен (рис. 1,2,3). Стена 1 оборонительная стена городища, сложенная из массивных (до 0,8 × 0,5 м), грубо обработанных блоков местного известняка. Вплотную к внутреннему фасу стены 1 была пристроена стена 2, которая принадлежала помещению, примыкавшему к городской оборонительной стене (рис. 1,3). Открытый внутренний фас кладки стены 2 состоял из трех рядов плохо обработанных камней длиной 0,3-0,4 м, кладка сохранилась на высоту 0,5-0,65 м. Пол этого помещения был прослежен на уровне основания нижнего ряда кладки стены 2 по всей площади шурфа. Он состоял из слоя плотной желтоватой глины с незначительным количеством известняковой крошки с глиняной промазкой в верхней части.

При разборке заполнения описываемого помещения обнаружен сравнительно немногочисленный, но достаточно разнообразный и показательный в хронологическом отношении материал. Здесь были найдены части хиосских прямогорлых амфор первых трех четвертей IV в. до н.э. (рис. 7,6). Другой обломок венца принадлежал мендейской амфоре пифоидного типа, относящейся к тому же периоду, что и амфоры, найденные в выбросе из грабительской ямы (рис. 7,5) [Монахов, 2003, c. 21-22, табл. 12,1-6]. К столовой керамике относились обломок венца чернолакового аттического канфара типа Cup-kantharos второй - третьей четвертей IV в. до н.э. [Rotroff, 1970, nrs. 672, 676] и обломок миски с закраиной каплевидного профиля (рис. 7,7). Подобные миски, широко распространенные в эллинистический период, хорошо известны по материалам различных античных памятников IV-III вв. до н.э. [Kasaev, 2002, р. 153-155]. В заполнении был также найден обломок венца коричневоглиняной кастрюли с округлым окончанием, имеющей многочисленные аналогии в причерноморских комплексах второй половины IV - III в. до н.э. [Kasaev, 2002, p. 156, 157; Кац и др., 2005, рис. 3,1-14]. К лепной керамике относился обломок отогнутого наружу венца, принадлежавший горшку наиболее распространенного среди материалов античных памятников Северного Причерноморья так называемого «степного» типа (рис. 7,14). Подобные сосуды повсеместно производились в Северном Причерноморье в пределах VI первой половины I в. до н.э. [Марченко, 1988, 76 сл.; Дашевская, 1991, табл. 10,17,20,21; $12,2,5 ; 26]$. Кроме того, при зачистке пола были найдены обломки чернолаковых и красноглиняных чаш и мисок (рис. 7,8-11), кухонных гончарного (рис. 7,13) и лепного горшков (рис. 7,15), прясло, изготовленное из ножки сосуда (рис. 7,12), и бронзовый рыболовный крючок. Однородный в хронологическом пла- 
не материал из заполнения и зачистки пола позволяет установить время функционирования указанного помещения в пределах IV века.

Ниже описанного уровня по всей площади шурфа был выявлен слой пожара, содержавший следы разрушений в виде обуглившихся кусков древесины и фрагментов штукатурки (рис. 2). Этот же слой был прослежен в шурфе 1. При его разборке был найден обломок венца хиосской амфоры (рис. 8,1), который принадлежал пухлогорлой амфоре развитого варианта 80-70 гг. V в. до н.э. [Монахов, 2003, с. 17-18]. Чернолаковая керамика слоя разрушения была представлена стенками сосудов открытого типа, а также обломками доньев килика с граффито «А» (рис. 8,3), относящегося к 80-70 гг. V в. до н.э. [Sparkes, Tallkot, 1970, nrs. 469-471], и скифоса (рис. 8,4), датирующегося около первой четверти того же столетия [Ibid, nr. 359]. К столовой керамике также относился край сероглиняного рыбного блюда (рис. 8,2). Кухонные сосуды были представлены обломками венцов лепных горшков, принадлежавших к описанному выше «степному», или I типу, по типологии К.К. Марченко (рис. 8,5-б).

Итак, в процессе раскопок в шурфах 1 и 2 были выявлены слои, связанные с хронологическими периодами истории Порфмия. Позднейшим из них, не считая засыпки в.п. $\mathrm{XX}$ в., является слой строительной нивелировки площади городища первой половины II в. до н.э. В шурфе 2003 г. была исследована часть помещения, функционировавшего в пределах IV в. до н.э. Ниже этих напластований в обоих шурфах был прослежен золистый слой, образовавшийся вследствие пожара и разрушений, произошедших около второй четверти $\mathrm{V}$ в. до н.э.

Хронологические этапы истории городища, выделенные, по данным разведочных шурфов 2002-2003 гг, соответствуют периодам истории Боспора. Таким образом, слой пожара можно соотнести с периодом дестабилизации греко-варварских взаимоотношений в регионе, вероятно, связанным с продвижением в регион кочевых племен в первой половине V в. до н.э. Следы пожаров, относящихся к этому времени, были зафиксированы во многих полисах Северного Причерноморья
[Vinogradov, Marčenko, 1989, p. 542-545; Виноградов, 2005, с. 238-245; 2006, с. 38]. Вероятно, Порфмий, как и другие центры Боспора, подвергся нападению и частичному или полному разрушению около второй четверти $\mathrm{V}$ в. до н.э. Материалы, полученные на основании раскопок участка А-Б в западной части городища, подтверждают эти выводы [Vachtina, 2003, p. 50-52; Вахтина, 2005, с. 46].

Следующий период истории городища, отображенный в описанных материалах, относится к IV в. до н.э. - времени правления династии Спартокидов, характеризующегося относительно мирным существованием, которое сопровождалось укреплением государства и расширением его границ. Комплекс жилой постройки, выявленный в шурфе 2003 г., дополняет сравнительно немногочисленные данные о городище в обозначенный период.

Следы активного строительства, относящиеся к первой половине II в. до н.э., вероятно, следует связывать с периодом так называемого «культурного возрождения» Боспора, происходившего на фоне относительной стабилизации греко-варварских отношений в регионе после сарматского нашествия [Виноградов, 2006, с. 39-41].

В заключение следует отметить, что материалы раскопок 2002-2003 гг. позволяют выделить несколько хронологических этапов существования городища, синхронно отображающих исторические периоды в истории Боспора V-II вв. до н.э. Хочется надеяться, что дальнейшие археологические исследования Порфмия уточнят хронологию этого «малого города» и дополнят картину исторического прошлого Боспора.

\section{ПРИМЕЧАНИЯ}

${ }^{1}$ Выражаю благодарность М.Ю. Вахтиной за предоставленную возможность изучить и опубликовать эти материалы, а также за важные уточнения и консультации в процессе подготовки статьи.

2 Подробнее см.: [Кастанаян, Вахтина, 1987; Вахтина, Виноградов, 2001; Вахтина, 2006; Вахтина, Стоянов, 2006].

3 Здесь и далее наименования типов и вариантов транспортных амфор приведены в соответствии с типологией С.Ю. Монахова [2003]. 


\section{ИЛЛЮСТРАЦИИ}
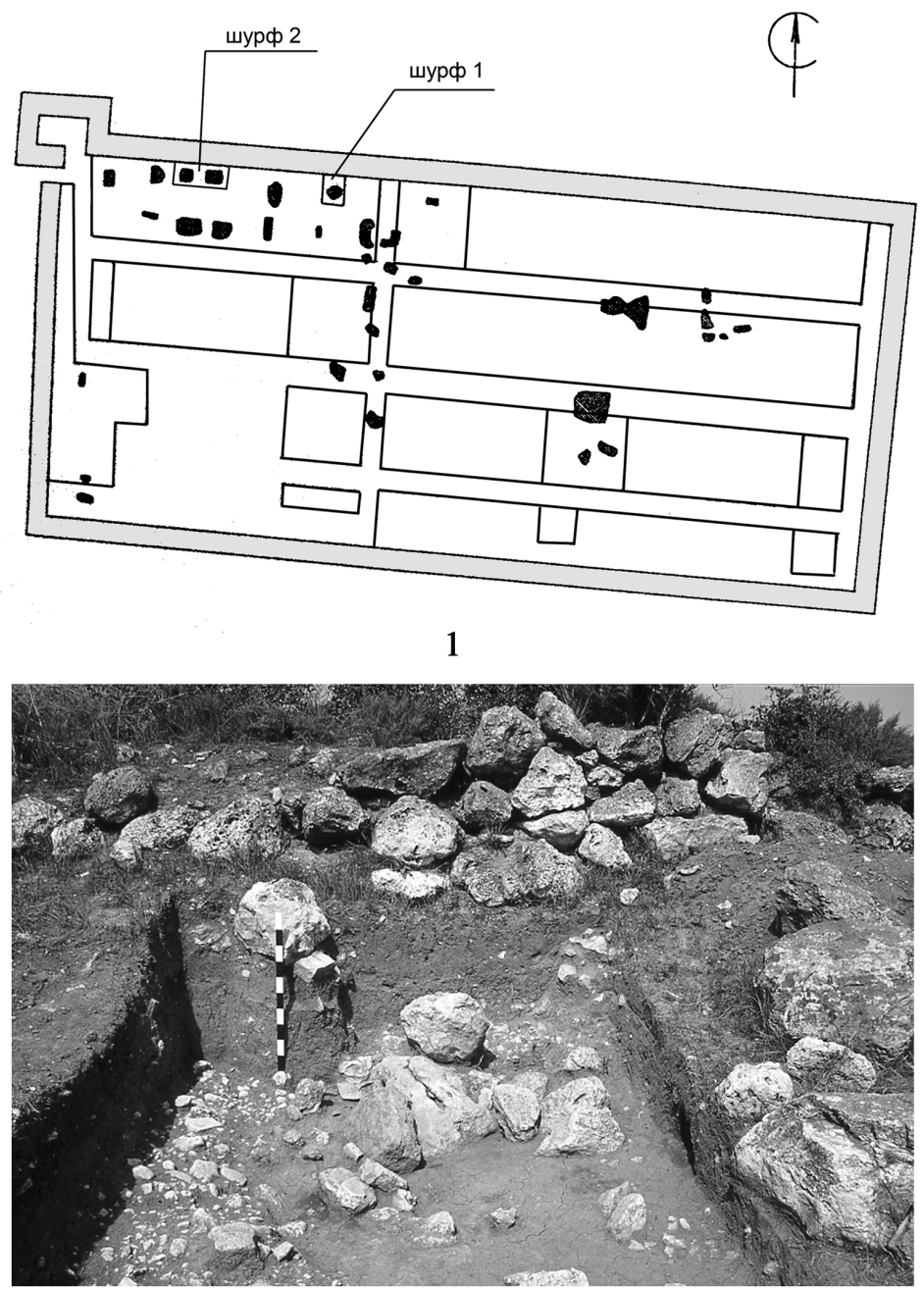

2

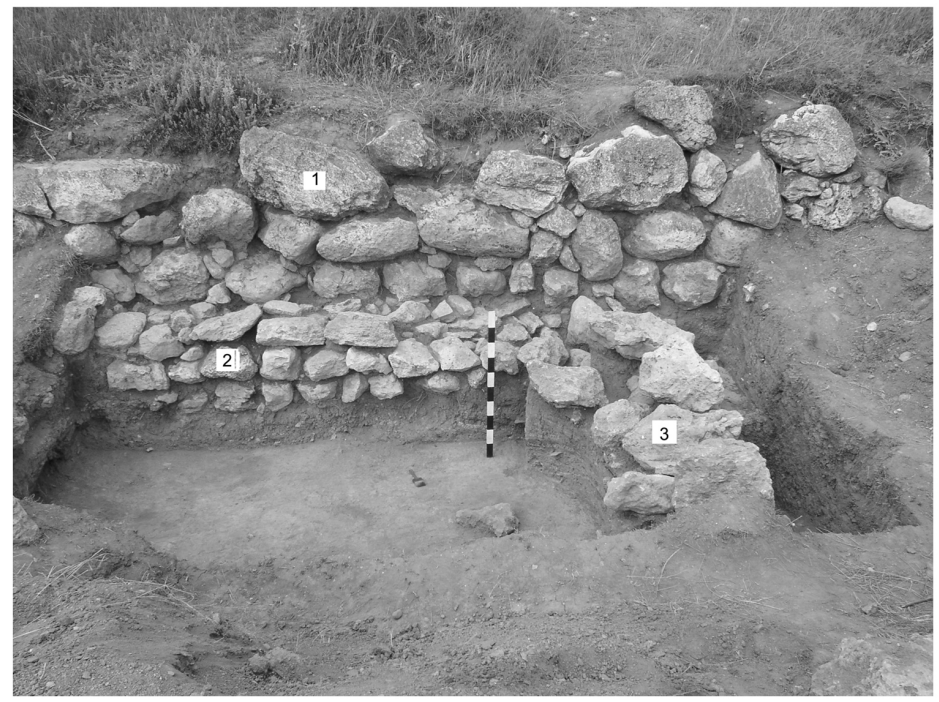

3

Рис. 1. Разведочные шурфы:

1 - схематический план Порфмия с указанием грабительских ям и разведочных шурфов 1-2; 2 - шурф $1 ; 3$ - шурф 2 Fig. 1. Exploration trenches:

1 - schematic plan of Porthmion with indication of robbery pits and archaeological trenches $1-2 ; 2-\operatorname{trench~} 1,3-\operatorname{trench} 2$ 


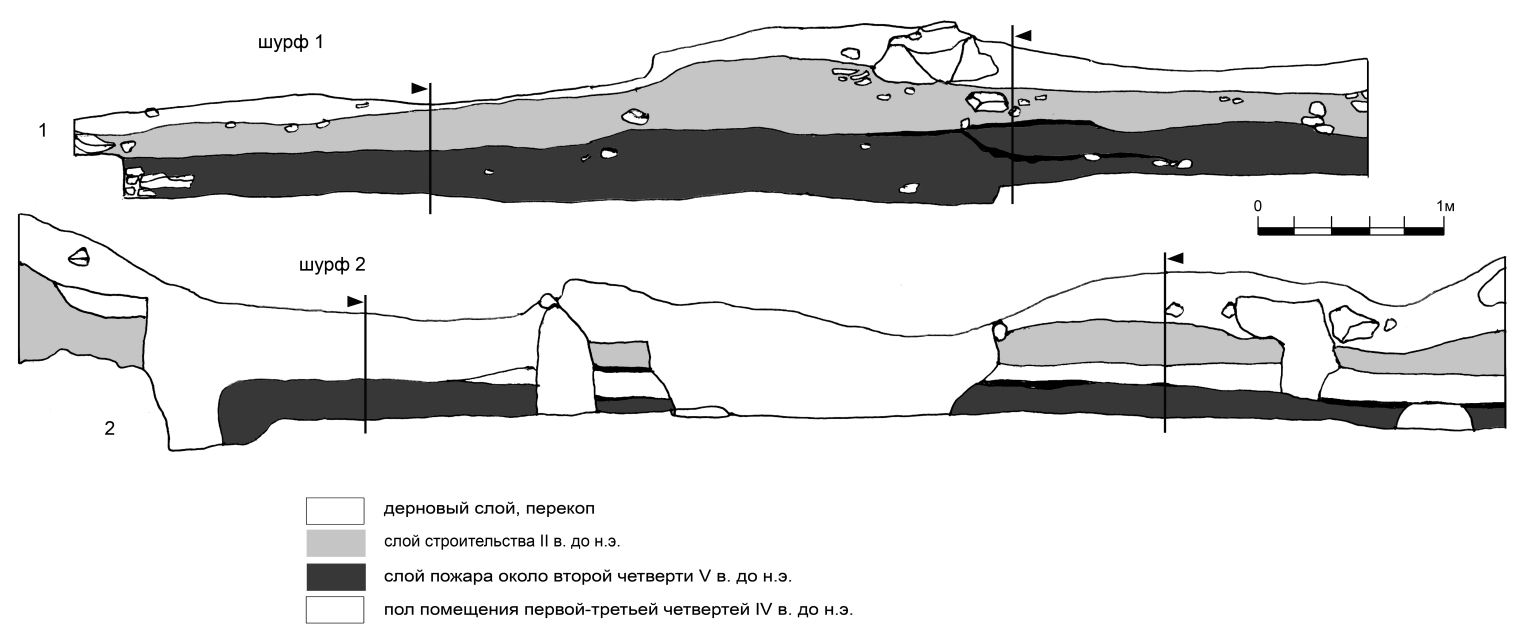

Рис. 2. Стратиграфия шурфов 1-2

Fig. 2. Stratification of trenches 1-2

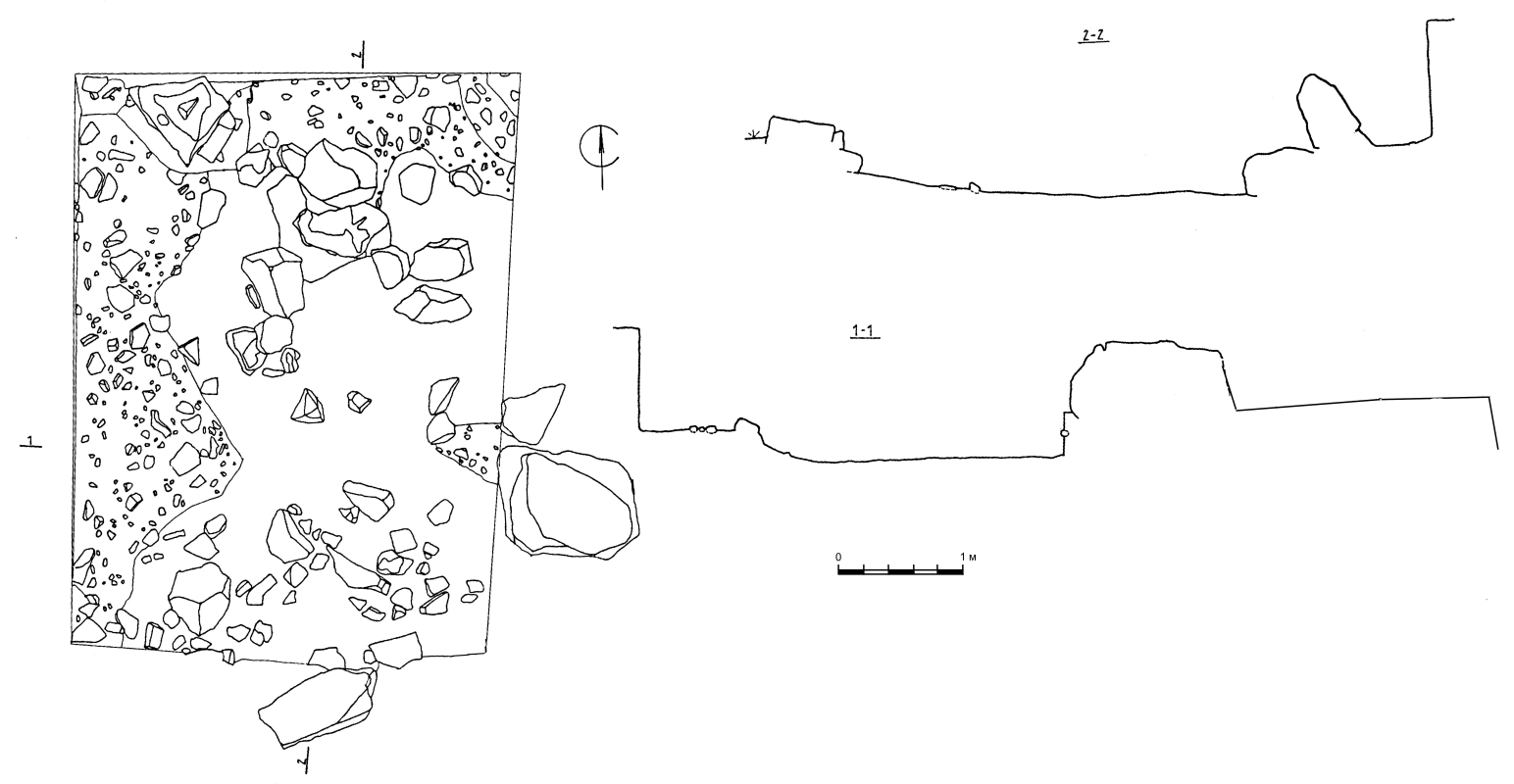

Рис. 3. Шурф 1, план и разрез

Fig. 3. Trench 1, plan and cross-section view 


\section{Монеты}

\begin{tabular}{|c|c|}
\hline Описание и определение моI & Д \\
\hline $\begin{array}{l}\text { Голова Аполлона вправо / лук и } \\
\text { стрела вправо, снизу: ПАN (рис. } 4,1)\end{array}$ & $\begin{array}{l}\text { Первая половина - середина II в. до н.э. [Шелов, } \\
\text { 1956, с. } 219 \text {, № 96, табл. VII,96]; 220-210 гг. до н.э. } \\
\text { [Анохин, 1986, с. 142, № 146, табл. 5,146] }\end{array}$ \\
\hline $\begin{array}{l}\text { Голова бородатого Сатира в } \\
\text { плющевом венке вправо / лук и стрела } \\
\text { вправо, снизу ФА (рис. 4,2) }\end{array}$ & $\begin{array}{l}\text { II в. до н.э. [Шелов, 1956, с. 221, № 112, } \\
\text { табл. IX, 112]; 220-210 гг. до н. э. [Анохин, 1986, } \\
\text { с. 142, № } 147, \text { табл. 5,147] }\end{array}$ \\
\hline
\end{tabular}

Примечание. Выражаю благодарность А.Е. Терещенко за определение и датировку монет.
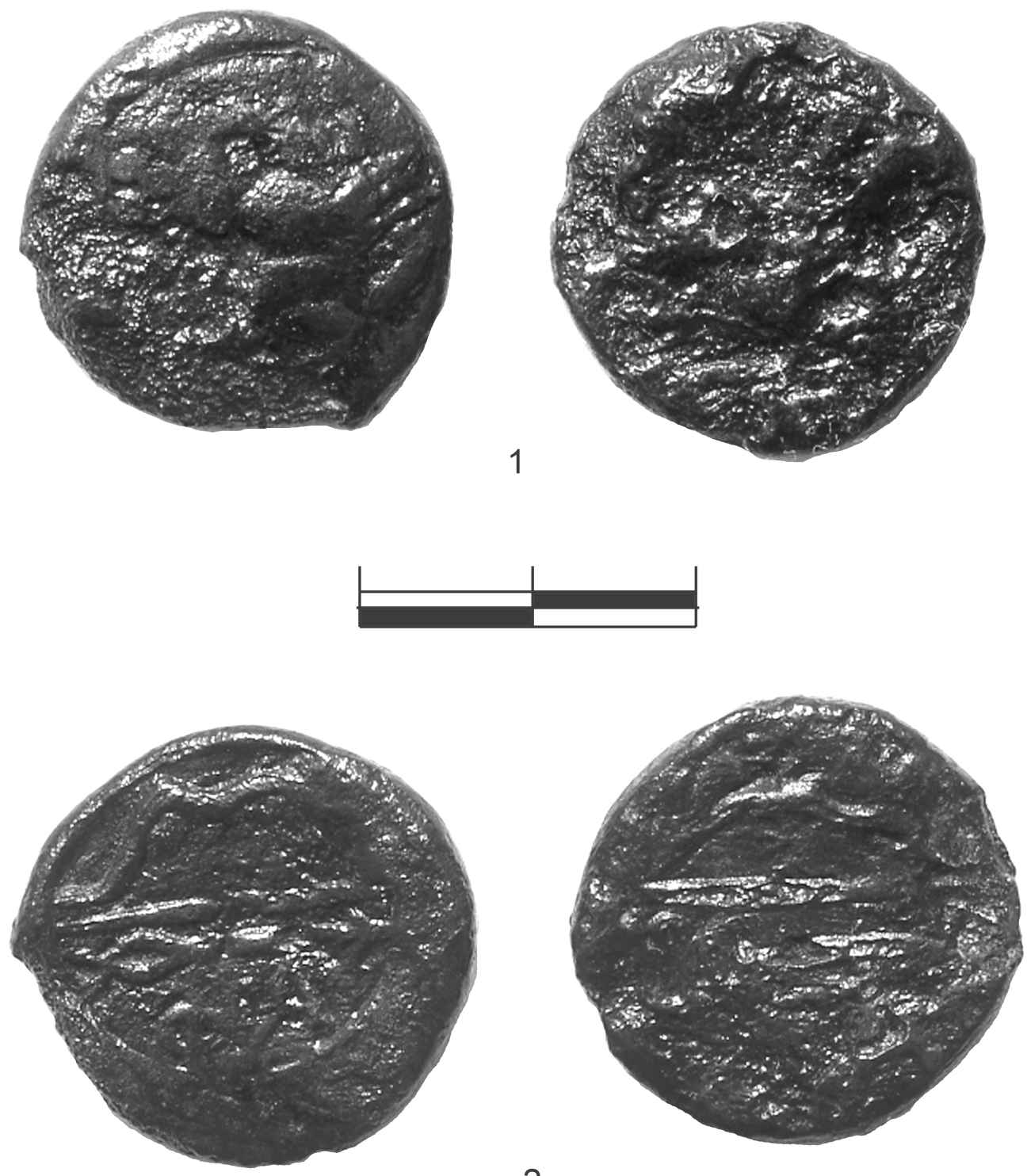

2

Рис. 4. Монеты:

1-2 - монеты (фото С.В. Яблочкина)

Fig. 4. Coins:

1-2 - Coins (photo by S.V. Yablochkin) 

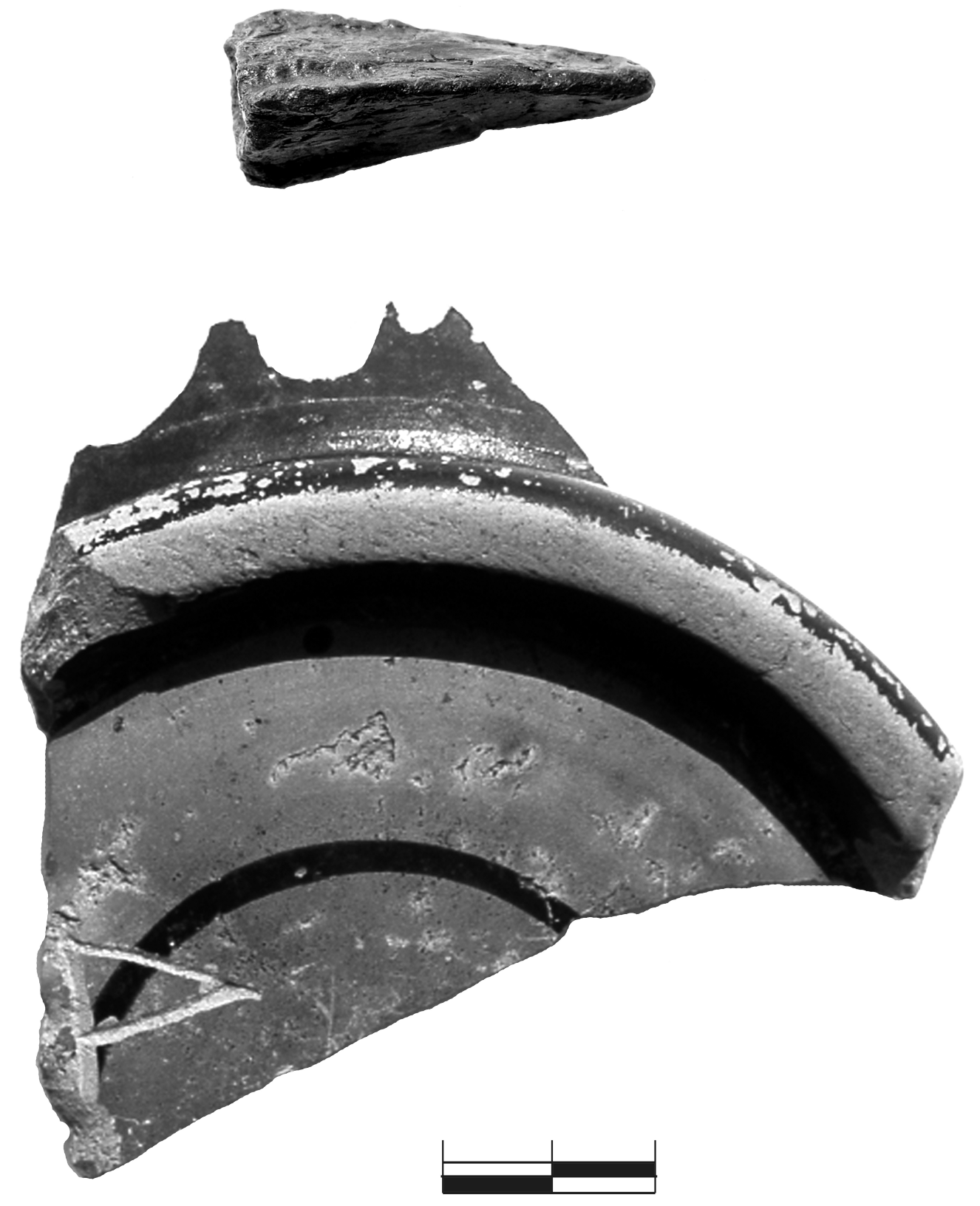

Рис. 5. Находки из горелого слоя в шурфе 1 (фото С.В. Яблочкина)

Fig. 5. Finds from the burnt layer in trench 1 (photo by S.V. Yablochkin) 

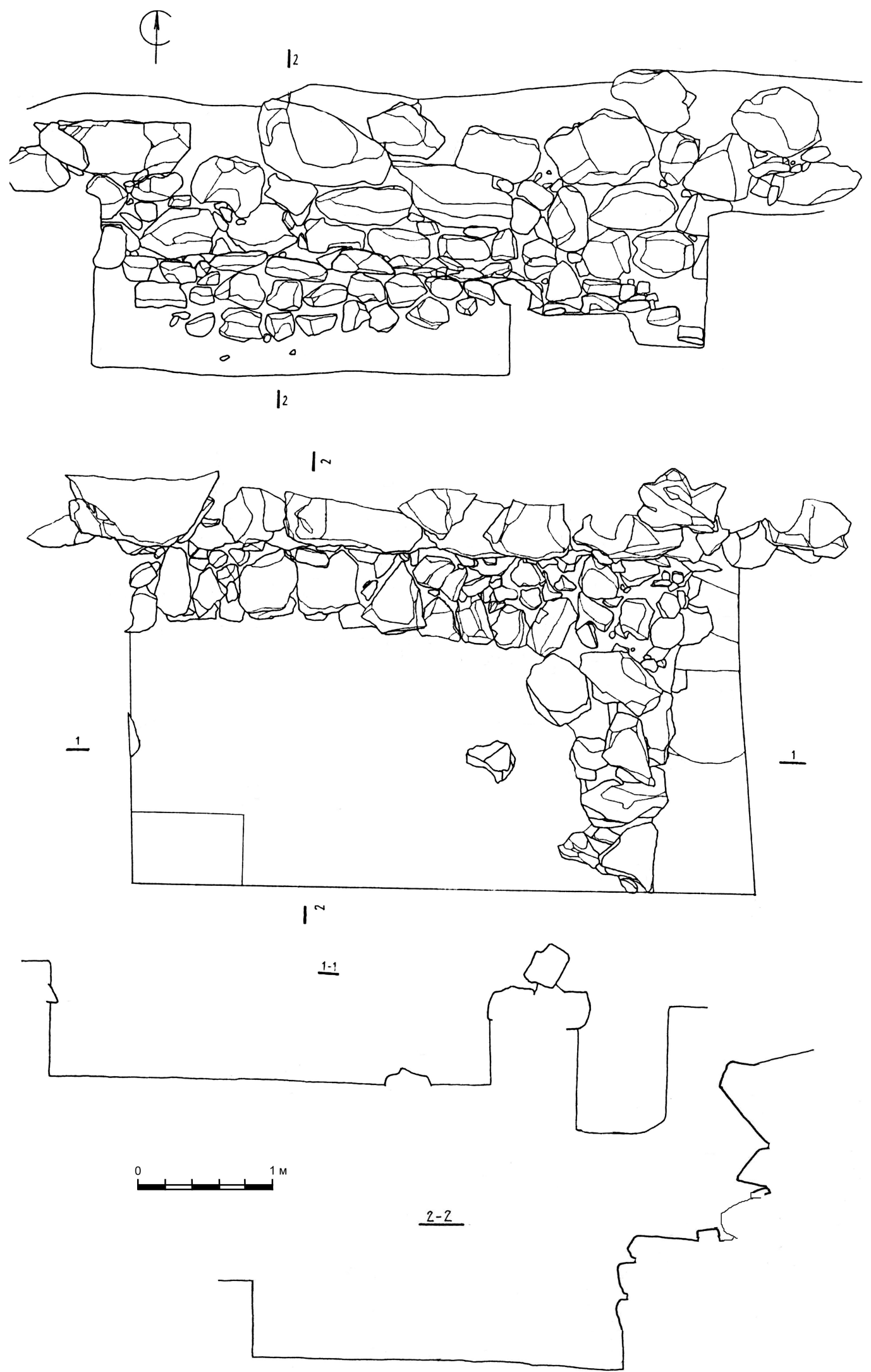

Рис. 6. Шурф 2, план и разрез

Fig. 6. Trench 2, plan and cross-section view 

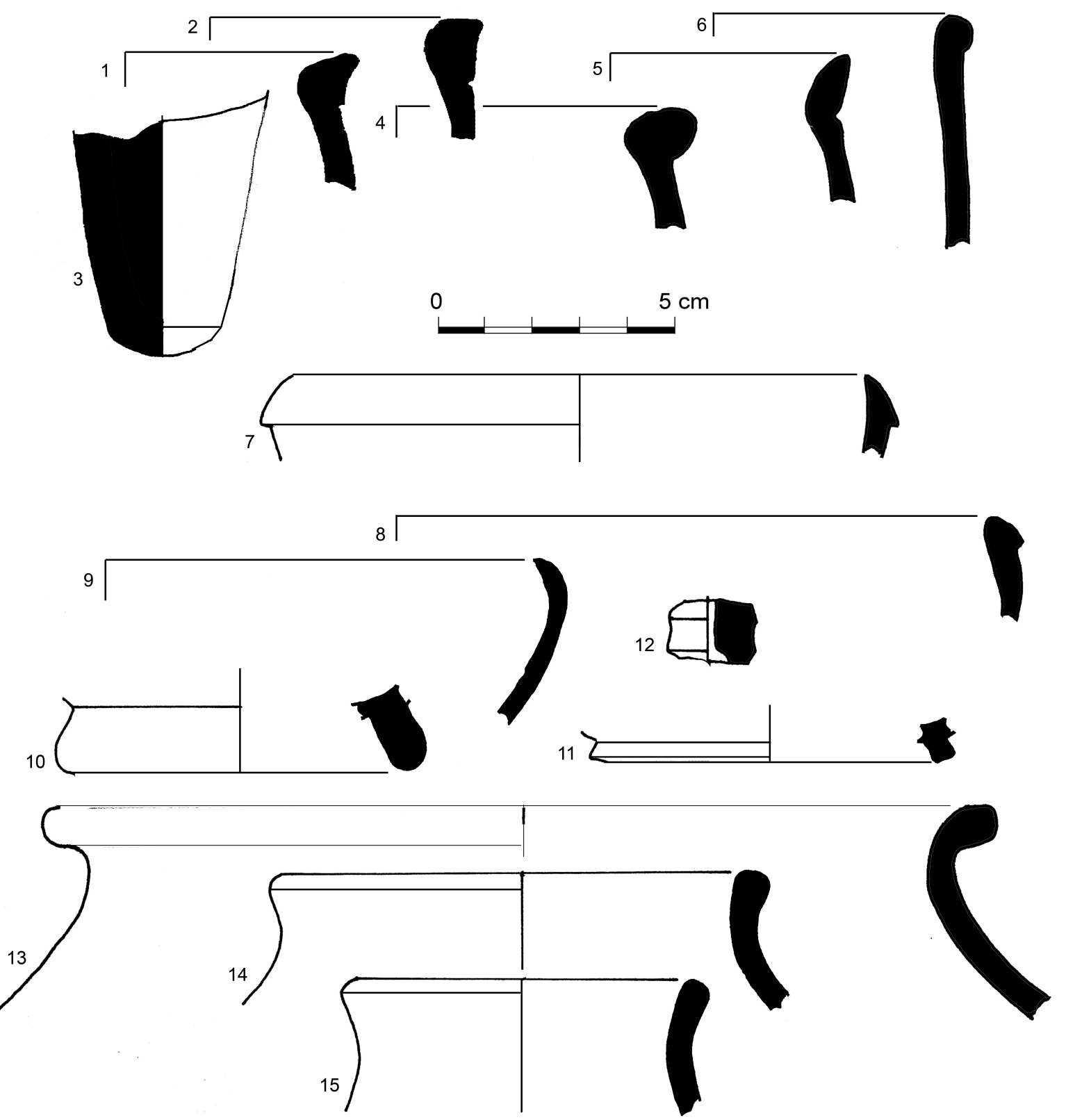

Рис. 7. Шурф 2:

1-3 - находки из выброса из грабительских ям; 4-15 - находки из заполнения и с уровня пола помещения

Fig. 7. Trench 2:

1-3 - finds from the ejection of the robbery pits; 4-15 - finds from the filling and the floor level of the room 

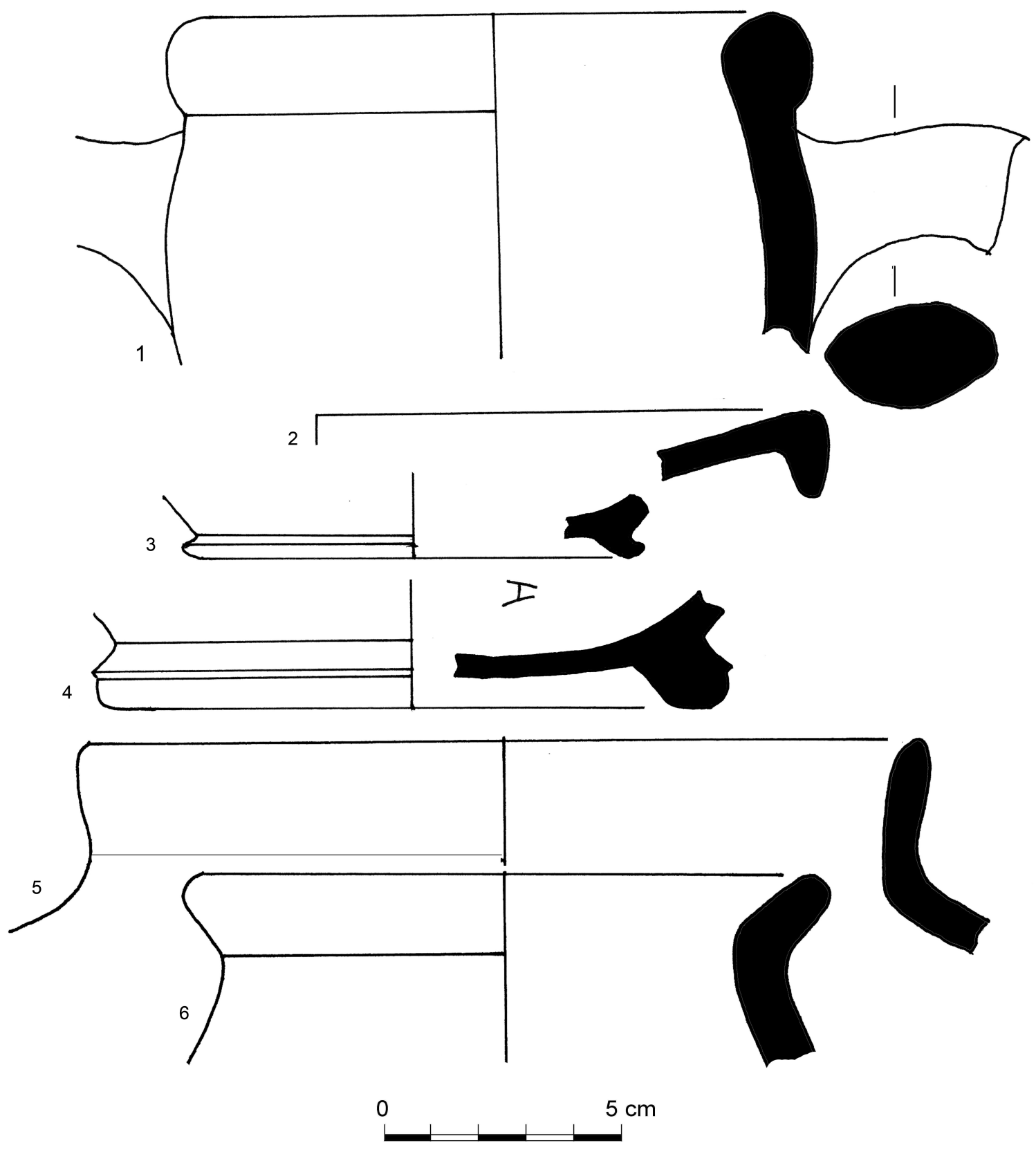

Рис. 8. Шурф 2:

1-6 - находки из горелого слоя в шурфе 2

Fig. 8. Trench 2:

$1-6$ - finds from the burnt layer in trench 2 


\section{СПИСОК ЛИТЕРАТУРЫ}

Анохин В. А., 1986. Монетное дело Боспора. Киев : Наукова думка. $223 \mathrm{c}$.

Вахтина М. Ю., 2005. Раскопки античного города Порфмий в Восточном Крыму // Проблемы изучения античной археологии Северного Причерноморья. СПб. : Исторический факультет СПбГУ. С. 54-61.

Вахтина М. Ю., 2006. Об архаическом Порфмии (по материалам раскопок 1986-1990; 2002-2005 гг.) // Боспорские исследования. Вып. 13. Симферополь-Керчь : Керченская городская типография. С. 31-46.

Вахтина М. Ю., Виноградов Ю. А., 2001. Еще раз о ранней фортификации Боспора Киммерийского // Боспорский феномен. Колонизация региона, формирование полисов, образование государства. Ч. І. СПб. : Государственный Эрмитаж. С. 41-45.

Вахтина М. Ю., Стоянов Р. В., 2006. Новые данные о некрополе Порфмия (по материалам археологических раскопок 2003-2005 гг.) // Apхеологические вести. № 13. С. 182-194.

Виноградов Ю. А., 2005. Боспор Киммерийский // Греки и варвары Северного Причерноморья в скифскую эпоху. СПб. : Алетейя. С. 211-296.

Виноградов Ю. А., 2006. Боспор Киммерийский: основные этапы истории в доримскую эпоху // Греки и варвары на Боспоре Киммерийском VII-I вв. до н.э. СПб. : Государственный Эрмитаж. С. 36-43.

Дашевская О. Д., 1991. Поздние скифы в Крыму // Свод археологических источников. Вып. Д 1-7. М. : Наука. 140 c.

Кастанаян Е. Г., 1958. Раскопки Порфмия в 1953 г. // Советская археология. № 3. С. 203-207.

Кастанаян Е. Г., 1971. Раскопки Порфмия // Археологические исследования на Украине в 1968 г. Киев : Наукова думка. С. 187-191.

Кастанаян Е. Г., 1972. Раскопки Порфмия в 1968 г. // Краткие сообщения института археологии АН СССР. № 130. М. : С. 77-82.

Кастанаян Е. Г., 1975. Итоги раскопок Порфмия эллинистической эпохи // Новейшие открытия советских археологов : тез. докл. конф. Ч. II. С. 103-104.

Кастанаян Е. Г., 1987. Порфмий // Études et travaux. Travaux du Centre d'archéologie méditerranéenne de l'académie polonais des sciences. T. XIII (26). Warszawa : Éditions scientifiques de Pologne. P. 162-168.

Кастанаян Е. Г., Вахтина М. Ю., 1987. Исследования Порфмия. Некоторые итоги и перспективы // Задачи советской археологии в свете решения XXVII съезда КПСС. М. : Изд-во Академии наук СССР. С. 60-61.
Кац В. И., Кузнецова Е. В., Монахов С. Ю., 2005. Новый керамический комплекс раннеэллинистического времени с Фанталовского полуострова // Тез. докл. IV Кубанской археологической Конференции. Краснодар : Изд-во Кубанского государственного университета. С. 107-118.

Марченко К. К., 1988. Варвары в составе населения Березани и Ольвии. Л. : Наука. 141 с.

Монахов С. Ю., 2003. Греческие амфоры в Причерноморье. Типология амфор ведущих центровэкспортеров товаров в керамической таре : каталог-определитель. М. ; Саратов : Киммерида : Изд-во Саратовского университета. $352 \mathrm{c}$.

Шелов Д. Б., 1956. Монетное дело Боспора VIII вв. до н.э. М. : Изд-во Академии наук CCCP. $220 \mathrm{c}$.

Kasaev. S. V., 2002. Commonware // Panskoe I: The monumental building U6. Vol.1. Aarhus : Aarhus University Press. $559 \mathrm{p}$.

Rotroff S. I., 1997. Hellenistic pottery. Athenian and imported wheelmade table ware and related materials // The Athenian Agora. Vol. XXIX (12). Princeton : American School of Classical Studies at Athens. 879 p.

Sparkes B. A., Tallkot L., 1970. Black and Plain Pottery of the $6^{\text {th }}, 5^{\text {th }}$ and $4^{\text {th }}$ centuries B.C. $/ /$ The Athenian Agora. Vol. XII. Princeton : American School of Classical Studies at Athens. $472 \mathrm{p}$.

Vachtina M. Ju., 2003. Archaic Buildings of Porthmion // Black Sea Studies. Vol. I. Aarhus : Aarhus University Press. S. 37-54.

Vinogradov Y. A., Marčenko K. K., 1989. Das nördliche Schwarzmeergebiet in der skythischen Epoche. Periodisierung der Geschichte // Klio: Beiträge zur alten Geschichte. Vol. 71. Berlin : De Gruyter. S. 539-549.

\section{REFERENCES}

Anohin V.A., 1986. Coinage of Bosporus. Kiev, Naukova dumka Publ. 223 p. (in Russian).

Vakhtina M.Yu., 2005. Excavations of the Ancient City of Porfmion in the Eastern Crimea. Problemy izucheniya antichnoy arkheologii Severnogo Prichernomor'ya. Saint Petersburg, Historical Department of SPBU, pp. 54-61. (in Russian).

Vakhtina M.Yu., 2006. On Archaic Porthmion (Based on the Excavations 1986-1990; 2002-2005). Bosphorus Studies, no. 13, pp. 31-46. (in Russian).

Vakhtina M.Yu, Vinogradov Yu.A., 2001. Once Again about the Early Fortification of Cimmerian Bosporus. Bosporskiy fenomen. Kolonizaciya regiona, formirovanie polisov, obrazovanie gosudarstva, Part. 1, Saint Petersburg, The State Hermitage Museum, pp. 41-45. (in Russian). 
Vakhtina M.Yu., Stoyanov R.V., 2006. New Data on the Necropolis of Porthmion (Archaeological Excavation of 2003-2005). Arkheologicheskie vesti, no. 13, pp. 182-194. (in Russian).

Vinogradov Yu.A., 2005. The Cimmerian Bosporus. Greki i varvary Severnogo Prichernomor'ya v skifskuyu ehpohu. Saint Petersburg, Aleteyya Publ. pp. 211-296. (in Russian).

Vinogradov Yu.A., 2006. The Cimmerian Bosporus: Main Stages of the History in the pre-Roman Era. Greki i varvary na Bospore Kimmeriyskom VII-I vv. do n.eh. Saint Petersburg, The State Hermitage Museum, pp. 36-43. (in Russian).

Dashevskaya O.D., 1991. Late Scythians in the Crimea. Svod arkheologicheskih Istochnikov, iss. D 17. Moscow, Nauka Publ. 140 p. (in Russian).

Kastanayan E.G., 1958. The Excavations of Porfmion in 1953. Sovetskaya arkheologiya, no 3, pp. 203 207. (in Russian).

Kastanayan E.G., 1971. The Excavations of Porfmion. Arkheologicheskie Issledovaniya na Ukraine v 1968 g. Kiev, Naukova dumka Publ, pp. 187191. (in Russian).

Kastanayan E.G., 1972. The Excavations of Porfmion in 1968. Brief Communication of the Institute Archaeology, no. 130, pp. 77-82. (in Russian).

Kastanayan E.G., 1975. Some Results of the Excavations of Hellenistic Porfmion. Noveyshie otkrytiya sovetskih arkheologov : tez. dokl. konf., part. II. Moscow, AS USSR, pp. 103-104. (in Russian).

Kastanayan E.G., 1987. Porfmion. Études et travaux. Travaux du Centre d'archéologie méditerranéenne de l'académie polonais des sciences, iss. XIII (26). Warszawa: Éditions scientifiques de Pologne, pp. 162-168. (in Russian).

Kastanayan E.G., Vahtina M.Yu., 1987. The Excavations of Porfmion. Some Results and Perspectives. Zadachi sovetskoy arheologii $v$ svete resheniya
XXVII s'ezda KPSS. Moscow, AS USSR, pp. 6061. (in Russian).

Kac V.I., Kuznecova E.V., Monakhov S.Yu., 2005. A New Ceramic Complex of Early Hellenistic Time from the Fantalovsky Peninsula : tez. dokl. IV Kubanskoy arkheolog. konf. Krasnodar, KubSU, pp. 107-118. (in Russian).

Marchenko K.K., 1988. The Barbarians in the Population of Berezan and Olbia. Leningrad, Nauka Publ. 141 p. (in Russian).

Monakhov S.Yu., 2003. Greek Amphorae in the Black Sea. Typology of Amphorae of the Leading Centers-Exporters of Goods in Ceramic containers : Catalog Identifier. Moscow Saratov, Kimmerida Publ. SSU. 352 p. (in Russian).

Shelov D.B., 1956. The Coinage of Bosporus in VIII Centuries BC. Moscow, AS USSR. 220 p. (in Russian).

Kasaev. S.V., 2002. Commonware. Panskoe I: The Monumental Building U6. Aarhus, Aarhus University Press. 559 p.

Rotroff S.I., 1997. Hellenistic Pottery. Athenian and Imported Wheelmade Table Ware and Related Materials. The Athenian Agora, iss. XXIX (12). Princeton, American School of Classical Studies at Athens. $879 \mathrm{p}$.

Sparkes B.A., Tallkot L., 1970. Black and Plain Pottery of the $6^{\text {th }}, 5^{\text {th }}$ and $4^{\text {th }}$ Centuries B.C. The Athenian Agora, iss. XII. Princeton, American School of Classical Studies at Athens. 472 p.

Vachtina M.Ju., 2003. Archaic Buildings of Porthmion. Black Sea Studies, iss. I. Aarhus, Aarhus University Press. pp. 37-54.

Vinogradov Yu.A., Marčenko K.K., 1989. Das nördliche Schwarzmeergebiet in der skythischen Epoche. Periodisierung der Geschichte. Klio: Beiträge zur alten Geschichte, iss. 71. Berlin, De Gruyter, pp. 539-549.

\section{Information about the Author}

Roman V. Stoyanov, Candidate of Sciences (History), Junior Researcher, Department of the History of Classical Culture, Institute for the History of Material Culture, RAS, Dvortsovaya Emb., 18, 191186 Saint-Petersburg, Russian Federation, roman.stoyanov@gmail.com, https://orcid.org/0000-0003-2290-154X

\section{Информация об авторе}

Роман Владимирович Стоянов, кандидат исторических наук, младший научный сотрудник Отдела истории античной культуры, Институт истории материальной культуры РАН, Дворцовая наб., 18, 191186 г. Санкт-Петербург, Российская Федерация, roman.stoyanov@gmail.com, https:// orcid.org/0000-0003-2290-154X 